Tropical Journal of Pharmaceutical Research, October 2009; 8 (5): 467-475

(C) Pharmacotherapy Group,

Faculty of Pharmacy, University of Benin,

Benin City, 300001 Nigeria.

All rights reserved.

Review Article

Available online at http://www.tjpr.org

\title{
Chronotherapeutics and Chronotherapeutic Drug Delivery Systems
}

\author{
J Sajan*, TA Cinu, AJ Chacko, J Litty and T Jaseeda \\ Department of Pharmaceutical Sciences, Mahatma Gandhi University, Cheruvandoor Campus, Ettumanoor, Kerala- \\ 686631, India.
}

\begin{abstract}
Chronotherapeutics refers to a treatment method in which in vivo drug availability is timed to match rhythms of disease, in order to optimise therapeutic outcomes and minimise side effects. It is based on the observation that there is an interdependent relationship between peak-to-trough rhythmic activity in disease symptoms and risk factors, pharmacologic sensitivity, and pharmacokinetics of many drugs. The specific time that patients take their medication is very important as it has significant impact on treatment success. Optimal clinical outcome cannot be achieved if drug plasma concentrations are constant. If symptoms of a disease display circadian variation, drug release should also vary over time. Drug pharmacokinetics can also be time-dependent; therefore, variations both in a disease state and in drug plasma concentration need to be taken into consideration in developing drug delivery systems intended for the treatment of disease with adequate dose at appropriate time. Various technologies such as time-controlled, pulsed, triggered and programmed drug delivery devices have been developed and extensively studied in recent years for chronopharmaceutical drug delivery. These, as well as pertinent issues, are addressed in this review.
\end{abstract}

Key words: Chronotherapeutics; Circadian rhythm; Chronopharmacokinetics; Chronopharmaceutics; Drug delivery systems 


\section{INTRODUCTION}

Many functions of the human body vary considerably in a day. These variations cause changes both in disease state and in plasma drug concentrations. Human circadian rhythm is based on sleep-activity cycle, is influenced by our genetic makeup and hence, affects the body's functions day and night (24-hour period) [1]. The dependence of bodily functions in certain disease states on circadian rhythm is well known. A number of hormones are released by the brain in the morning, while others are released during sleep. Blood pressure and heart rate are highest during the hours of 6.00 a.m. to 12.00 noon [2].

Diseases, such as hypertension, asthma, peptic ulcer, arthritis, etc, follow the body's circadian rhythm [3]. For example, osteoarthritis worsens during the day and is most bothersome in the evenings but for people with rheumatoid arthritis, the pain usually peaks in the morning and decreases as the day progresses. Cardiovascular diseases such as hypertension and angina, and chest pain, also follow a definite circadian rhythm. Epidemiologic studies have documented the heightened morning-time risk of angina, myocardial infarction, and stroke [4].

The goal in drug delivery research is to develop formulations to meet therapeutic needs relating to particular pathological conditions. Research in the chronopharmacological field has demonstrated the importance of biological rhythms in drug therapy, and this has brought a new approach to the development of drug delivery systems. Optimal clinical outcomes cannot be achieved if drug plasma concentrations are constant. If symptoms of a disease display circadian variation, drug release should also vary with time. Utilization of different technologies in the development of time-controlled, pulsed, triggered and programmed drug delivery devices has intensified in recent years.

Another issue that has emerged from circadian variation of physiological function is that drug pharmacokinetics can be timedependent (i.e., chronopharmacokinetics) [5]. Therefore, variation in disease state and drug plasma concentration need to be taken into consideration in the development of drug delivery systems intended for the treatment of diseases with adequate dose at the appropriate time. The term, 'Chronopharmaceutic drug delivery system', is used to describe a kind of drug formulation which can cause circadian variation in drug plasma levels [6-8].

\section{CHRONOTHERAPEUTICS}

The term "chrono" basically refers to the observation that every metabolic event undergoes rhythmic changes in time. Researchers have concluded that all living organisms are composites of rhythms with varying frequencies that may range from seconds to seasons. Perhaps the best known and studied chronobiologic frequency is the circadian rhythm which approximates the earth's 24-hour rotation around the sun [9]. Researchers have recently concluded that both disease states and drug therapy are affected by a multitude of rhythmic changes that occur within the human body [3].

Chronotherapeutics refers to a treatment method in which in vivo drug availability is timed to match rhythms of disease in order to optimize therapeutic outcomes and minimize side effects. It is based on the observation that there is an interdependent relationship between the peak-to-trough rhythmic activity in disease symptoms and risk factors, pharmacologic sensitivity, and pharmacokinetics of many drugs [10]. As more continues to be learned about chronobiology and chronotherapeutics, it is becoming increasingly more evident that the specific time that patients take their medication may be even more significant than was recognized in the past. The tradition of prescribing medication at evenly spaced time intervals throughout the day, in an attempt to maintain constant drug levels 
throughout a 24-hour period, may be changing as researchers' report that some medications may work better if their administration is coordinated with day-night patterns and biological rhythms [1].

\section{Diseases and chronotherapeutics}

Up to now, design of drug delivery systems has been governed by the homeostatic theory [11]. This theory is based on the assumption of biological functions that display constancy over time. However, chronobiological studies have established circadian rhythm for almost all body functions, e.g., heart rate, blood pressure, body temperature, plasma concentration of various hormones, gastric $\mathrm{pH}$ and renal function [12]. It has become apparent that rhythmic processes are indispensable for the treatment of human diseases. Just as physiological functions vary over time, pathological states of disease have circadian rhythms. Epidemiological studies have documented the elevated risk of disease symptoms during the 24-hour cycle (see Fig. 1) $[13]$.

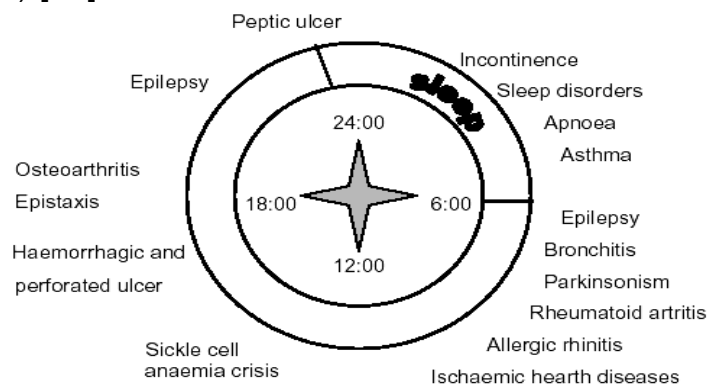

Figure 1: Diseases Inown to display circadian rhythm

The potential benefits of chronotherapeutics have been demonstrated in the management of a number of diseases. In particular there is a great deal of interest in how chronotherapy can particularly benefit patients suffering from allergic rhinitis, rheumatoid arthritis and related disorders, asthma, cancer, cardiovascular diseases, and peptic ulcer disease [3].
Patients with allergic rhinitis often report that they suffer their worst symptoms when they wake up in the morning. Patients may obtain better results in controlling this morning discomfort if they were to take a long-acting antihistamine at night rather than taking the medication in the morning as is frequently recommended [1].

\section{Anti-inflammatory therapy}

In the case of individuals who suffer from rheumatoid arthritis and related painful joint disorders, the non-steroidal anti-inflammatory agents (NSAIDs) such as ibuprofen may be more effective at relieving pain, if the drug is administered at least 4 to 6 hours before the pain reaches its peak. It will be more helpful if arthritis patients take the NSAIDs before bed time if they experience a particularly high level of discomfort in the morning [13].

\section{Anti-asthma therapy}

It has been estimated that symptoms of asthma occur 50 to 100 times more often at night than during the day [14]. Many circadian-dependent factors appear to contribute to the worsening of nocturnal asthmatic symptoms. For example, cortisol (an anti-inflammatory substance) levels were highest at the time of awakening and lowest in the middle of the night, and histamine (a mediator of bronchoconstriction) concentrations peaked at a level that coincided with the greatest degree of bronchoconstriction at 4:00 am [3]. A research finding also reveals that theophylline absorption is slower at night [9]. The enhanced understanding of the chronobiological impact upon the pathology of asthma, and the pharmacology and pharmacokinetics of the drugs used in its management, have led to new approaches to disease management and enhanced patient care.

\section{Chemotherapy}

Antineoplastic drugs cause cytotoxic effects 
on healthy and diseased tissues. As would be expected, the biological rhythms of both healthy and tumor cells may influence the susceptibility of normal and malignant cells to these agents [14]. It has been demonstrated that "susceptibility rhythms" to drugs may differ between healthy tissue and cancerous tissue. Therefore, the "correct" timing of drug treatment may reduce host toxicity, increase maximum drug tolerance, and ultimately result in better tumor management. The pharmacologic and pharmacokinetic properties of the drug, rhythmic changes in DNA and RNA synthesis, RNA translational activity and mitotic activity may influence tumor cell susceptibility [3]. It appears that the timing of drug administration in the treatment of cancer can have a significant impact upon treatment success.

\section{Cardiovascular therapy}

The differences in patterns of illness between day and night for cardiovascular disorders such as hypertension, angina, heart attack, sudden cardiac death and stroke have been documented [1]. Medications have been formulated, and dosing schedules established, in an attempt to provide appropriate concentration of a drug in the target area of the body when the drug is most needed[1]. For example, it has often been found that the blood pressure of a hypertensive patient increases rapidly in the morning after awakening, typically peaks in the middle to late time of the day, decreases in the evening, and is lowest while the patient sleeps at night [1]. It may also be important to recognize that the risk of heart attack appears to be greatest during the early morning hours after awakening. Currently, there are antihypertensive products in the market that are chronotherapeutic medications with novel drug delivery systems, releasing drug during the vulnerable period of 6 am to noon upon administration of medications at $10 \mathrm{pm}$. Some of these are listed in Table 1.
Table 1: Some chronotherapeutic antihypertensive products

\begin{tabular}{|c|c|c|}
\hline Product & $\begin{array}{l}\text { Generic } \\
\text { name }\end{array}$ & Manufacturer \\
\hline $\begin{array}{l}\text { InnoPran } \\
\text { XL }\end{array}$ & Propranolol & $\begin{array}{l}\text { GlaxoSmithKline } \\
\text { USA }\end{array}$ \\
\hline $\begin{array}{l}\text { Cardizem } \\
\text { LA }\end{array}$ & Diltiazem & $\begin{array}{l}\text { Biovail Corporation } \\
\text { Mississauga, ON } \\
\text { Canada }\end{array}$ \\
\hline $\begin{array}{l}\text { Verelan } \\
\text { PM }\end{array}$ & Verapamil & $\begin{array}{l}\text { Schwars Pharma } \\
\text { Monheim, Germany }\end{array}$ \\
\hline $\begin{array}{l}\text { Covera } \\
\text { HS }\end{array}$ & Verapamil & $\begin{array}{l}\text { G. D. Searle } \\
\text { (a division of Pfizer), } \\
\text { NY, USA }\end{array}$ \\
\hline
\end{tabular}

\section{Anti-ulcer therapy}

It is well established that patients with peptic ulcer disease often experience the greatest degree of pain near the time that they go to bed, as the rate of stomach acid secretion is highest at night [1]. The timing of administration of ulcer medications has a significant impact on their therapeutic effect.

\section{CHRONOPHARMACOKINETICS}

Chronopharmacokinetics entails the study of temporal changes in drug absorption, distribution, metabolism and excretion [15]. Pharmacokinetic parameters, which are conventionally considered to be constant in time, are influenced by various physiological functions displaying circadian rhythm. Circadian changes in gastric acid secretion, gastrointestinal motility, gastrointestinal blood flow, drug protein binding, liver enzyme activity, renal blood flow and urinary $\mathrm{pH}$ may play a role in time-dependent variation of drug plasma concentration [15-17]. Numerous chronopharmacokinetic studies have been conducted over the last 20 years $[15,18]$. The results of these studies demonstrate that time of administration affects drug kinetics.

Studies in man have been reported, particularly in relation to cardiovascular active 
drugs, non-steroidal anti-inflammatory drugs (NSAIDs), local anaesthetics, anticancer drugs, psychotropic drugs, antibiotics and anti-asthmatic drugs [16]. Most of the drugs seem to have a higher rate or extent of bioavailability when they are taken in the morning than when they are taken in the evening.

\section{Antihypertensive drugs}

For example, with cardiovascular drugs such as nifedipine, oral nitrates and propranolol, plasma peak concentration is twice as high and time to reach peak concentration is shorter after morning dosing compared with evening dosing [15]. Such a variation was not detected when sustained release dosage forms of nifedipine and isosorbide mononitrate were used. The underlying mechanisms of their chronopharmacokinetic pattern involve a faster gastric emptying time and a greater gastrointestinal perfusion in the morning. Shiga et al documented that atenolol, in contrast to propranolol, is not absorbed more rapidly after morning administration compared with post-evening administration [18]. This confirms that the absorption rate of a lipophilic, but not hydrophilic, drugs is faster after morning dosing [19].

\section{Anti-inflammatory drugs}

Studies on NSAIDs, e.g., indomethacin and ketoprofen, have also shown that these drugs have a greater rate and/or extent of bioavailability when they are given in the morning than when they are given in the evening. Markedly higher ketoprofen plasma peaks were observed after administration at 07:00 than after administration at other times [20]. Earlier and higher peak concentrations were obtained when indomethacin was given at $07: 00$ or 11:00 than at other times of the day or night [21]. Better morning absorption has also been observed with controlled release indomethacin and ketoprofen formulations [22,23]. The clinical relevance of such variations is that high plasma concentrations correlate with high incidence of adverse effects. It has been suggested that morning absorption for these drugs is better than night-time absorption. Greater blood flow of the gastrointestinal tract in the morning than in the evening may explain this phenomenon. Circadian changes in renal function, plasma protein binding or hepatic blood flow could also explain temporal variation in drug plasma levels. Many variables are known to influence pharmacokinetics.

In chronopharmacokinetic studies, it is important to strictly control the time of drug administration. When symptoms of the disease are circadian-dependent or drug used has a narrow therapeutic range, a chronophannacokinetic study should be performed. The studies should be conducted under controlled conditions, including fasting time, composition of meals and posture.

\section{CHRONOTHERAPEUTIC DRUG DELIVERY SYSTEMS}

Controlled release formulations can be divided into subgroups of rate-controlled release, delayed-release and pulsed-release formulations. Delayed-release formulations include time-controlled release and sitespecific dosage forms [24-26]. When constant drug plasma levels need to be avoided, as in chronotherapy, time-controlled or pulsed-release formulations are preferable, especially in the treatment of early morning symptoms. By timing drug administration, plasma peak is obtained at an optimal time and the number of doses per day can be reduced. Saturable first-pass metabolism and tolerance development can also be avoided [27]. Various technologies to develop timecontrolled peroral drug delivery systems have been extensively studied in recent decades. Some of these systems are discussed in the following subsections.

\section{Enteric-coated systems}

Enteric coatings have traditionally been used 
to prevent the release of a drug in the stomach (see Fig 2). Enteric coatings are $\mathrm{pH}$ sensitive and drug is released when $\mathrm{pH}$ is raised above 5 in the intestinal fluid. These formulations can be utilised in time-controlled drug administration when a lag time is needed. Because of the unpredictability of gastric residence, such systems cannot be the first choice when a time-controlled release is required. In the treatment of nocturnal asthma, a salbutamol formulation containing a barrier coating which is dissolved in intestinal $\mathrm{pH}$ level above about 6 , has been successfully used [28]. The system contains a core which is film coated with two polymers, first with HPMC and then with a gastro-resistant polymer (Eudragit ${ }^{\circledR}$ L30D). In this system the duration of the lag phase in absorption can be controlled by the thickness of the HPMC layer.

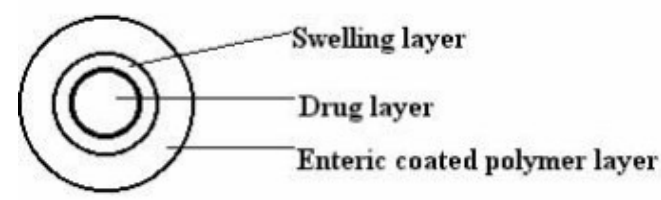

Figure 2: Schematic representtion of enteric coated system

\section{Layered systems}

These are one or two impermeable or semipermeable polymeric coatings (films or compressed) applied on both sides of the core [29]. To allow biphasic drug release, a three-layer tablet system was developed [24]. The two layers both contain a drug dose. The outer drug layer contains the immediately available dose of drug. An intermediate layer, made of swellable polymers, separates the drug layers. A film of an impermeable polymer coats the layer containing the other dose of drug. The first layer may also incorporate a drug-free hydrophilic polymer barrier providing delayed $(5 \quad$ h) drug absorption. Conte et al has also studied a multi-layer tablet system (Geomatrix ${ }^{\circledR}$ ). It consists of a hydrophilic matrix core containing the drug dose. This kind of three- layer device has been used in the treatment of Parkinsonian patients using L-dopa/benserazide [30]. Night-time problems and early-morning symptoms of Parkinsonism can be avoided by using a dual-release Geomatrix@ formulation, which allows daily doses of drug to be reduced and leads to extent of bioavailability $40 \%$ greater than when a traditional controlled release formulation is employed.

\section{Time-controlled explosion systems (TES)}

These have been developed for both single and multiple unit dosage forms [31,32] . In both cases, the core contains the drug, an inert osmotic agent and suitable disintegrants. Individual units can be coated with a protective layer and then with a semipermeable layer, which is the rate controlling membrane for the influx of water into the osmotic core. As water reaches the core, osmotic pressure is built up. The core ultimately explodes, with immediate release of the drug. The explosion of the formulation can also be achieved through the use of swelling agents. Lag time is controllable by varying the thickness of the outer polymer coating.

\section{Sigmoidal release systems (SRS)}

For the pellet-type multiple unit preparations, SRS containing an osmotically active organic acid have been coated with insoluble polymer to achieve different lag-times [33-35]. By aplying different coating thicknesses, lag times in vivo of up to 5 hours can be achieved. Release rates from SRS, beyond the lag time, has been found to be independent of coating thickness.

\section{Press-coated systems}

Delayed-release and intermittent-release formulations can be achieved by press-coating. Press-coating, also known as compression coating, is relatively simple and cheap, and may involve direct compression of both the core and the coat, obviating the 
need for a separate coating process and the use of coating solutions. Materials such as hydrophilic cellulose derivatives can be used and compression is easy on a laboratory scale. On the other hand, for large-scale manufacture, special equipment is needed. The major drawbacks of the technique are that relatively large amounts of coating materials are needed and it is difficult to position the cores correctly for the coating process [36].

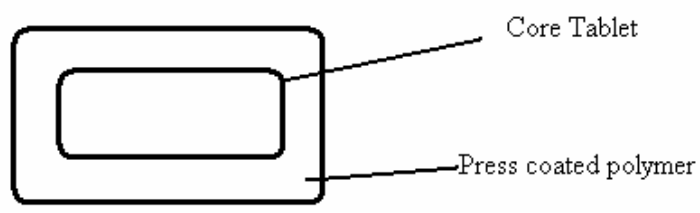

Figure 3: Schematic representation of a presscoated system

In recent years, various controlled release, especially time-controlled release, drug delivery systems based on compression coating technology have been studied. Most of such formulations release drug after a lag phase, followed by a rapid dissolution of the core. Conte et al have developed a presscoated device in which the inner core contains the drug and the outer coat is made of different types of polymers. The outer barrier, which controls drug release, can be either swellable or erodible. Lag times can be varied by changing the barrier formulation or the coating thickness $[7,8]$. Matsuo et al have developed a diltiazem hydrochloride formulation intended for use in the treatment of time-related symptoms of ischaemic heart disease and hypertension [37]. The tablet consists of a core, which contains the drug, and a coat formed by compressing hydroxyethylcellulose. Diltiazem is rapidly released after a delay of several hours. Marvola et al have developed a press-coated tablet formulation in which most of the total amount of drug is in the tablet core [38]. Hydrophilic polymers such as hydroxypropyl methylcellulose and sodium alginate have been used in the coat to control drug release as illustrated in Fig. 3. The extent of bioavailability of furosemide, ibuprofen and salbutamol sulphate from the system developed has been found to be satisfactory [39-42].

\section{Other systems}

Elementary osmotic pumps can be useful for delivering drugs based on chronotherapeutic requirements. One type of elementary osmotic pump can deliver salbutamol, initially at a constant delivery rate, then as a final pulse dose [43]. Such a system could deliver a dose during a nocturnal asthma attack. The first chronotherapeutic system for the treatment of hypertension and angina pectoris, a controlled onset extended-release (COER-24) verapamil formulation, was developed and registered in USA [44,45]. This formulation was tailored to the circadian rhythm of blood pressure and heart rate to better cover early morning symptoms of cardiovascular diseases. COER-24 is an osmotically controlled single unit system. Around the device, which consists of a drug layer and a push layer, are two membranes. The first is a semi-permeable insoluble membrane while the second is a releasedelaying hydrophilic polymer coat. Gastrointestinal fluid penetrates the semipermeable membrane, and as it enters the drug layer and push layer via the hydrated coat (within 4 to 5 hours), the push layer expands, pressing against the drug layer and causing drug release at a constant rate for 18 hours. If taken at bedtime, the system provides optimal drug concentration when the patient wakes up and during day time.

Pulsinocapŏ is a delivery system which releases drug contents at a predetermined time or at a specific site within the gastrointestinal tract [46]. Each capsule is composed of a water insoluble body and a water soluble cap, and also contains the drug dose which is sealed with a hydrogel plug. At a predetermined time after ingestion, the swollen plug is ejected from the capsule and the drug is then released into the small intestine or colon. The dimension of the plug and its position in the capsule can be varied 
and the system delivers drug at exactly the programmed time, 1 to 10 hours after drug administration, to various regions of the gut.

\section{CONCLUSION}

Research in chronopharmacology has demonstrated the importance of biological rhythms in drug therapy and this has led to a new approach to the development of drug delivery systems. Optimal clinical outcome cannot be achieved if drug plasma concentrations are constant. If symptoms of a disease display circadian variation, drug release should also vary over time. Different technologies have been applied to develop time-controlled, pulsed, triggered and programmed drug delivery devices in recent years. Since it is seems that timing of drug administration in disease therapy has significant impact upon treatment success, chronotherapeutics remains an important area for continuing research.

\section{REFERENCES}

1. Evans RM, Marain C. Taking Your Medication: $A$ Question of Timing. American Medical Association: 1996:3-8 Evans RM, Marain C, et al, editors.eds. Taking Your Medication: A Question of Timing. Chicago, IL: American Medical Association; 1996. pp 3-8.

2. Michael PL. Chronobiology and Chronotherapeutics - Possible Strategy for Hypertension and Ischemic Heart Disease [Cited 2009 May 28]. Available from: http://www.touchcardiology. com/articles/chronobiology-and-chronotherape utics-possible-strategy-hypertension-and-ische mic-heart-diseitishicalournal.

3. Ura J, Shirachi D, Ferrill M. The chronotherapeutic approach to pharmaceutical treatment. California Pharmacist. 1992; 23(9): 46-53.

4. Subal CB. Chronotherapeutics: Optimising drug delivery [cited 2005 August 17]. Available from: www.pharmabiz.com/article/detnews. asp? Arch=a\&articleid= 28993\&sectionid=46

5. Bruguolle $B$, Lemmer $B$. Recent advances in chronopharmacokinetics: methodological problems. Life Sci 1993; 52: 1809-1824.

6. Halsas M, Hietala J, Veski $P$, Jürjenson $H$, Marvola M. Morning vs. evening dosing of ibuprofen using conventional and time-controlled release formulations. Int J Pharm 1999; 189: 179-185.

7. Halsas $M$, Ervasti $P$, Veski $P$, Jürjenson $H$, Marvola $M$. Biopharmaceutical evaluation of timecontrolled press-coated tablets containing polymers to adjust drug release. Eur J Drug Metabol Pharmacokinet 1998; 23: 190-196.

8. Halsas $M$, Simelius $R$, Kiviniemi $A$, Veski $P$, Jürjenson $H$, Marvola $M$. Effect of different combinations of HPMC on bioavailability of ibuprofen from press-coated time-controlled tablets. STP Pharma Sci. 1998; 8: 155-161.

9. Lamberg L. Chronotherapeutics: implications for drug therapy. American Pharmacy 1991; NS31(11): 20-23.

10. Traynor K, Newton DW, Hrushesky JM, Reiter RJ. A pharmacist's primer on chronotherapeutics. American Pharmacy. 1992; NS32(3): 261-269.

11. Homeostasisis. [Cited 2009 May 19]. Available from: $\quad$ http://www.bio-medicine.org/biologydefinition/homeostasis/

12. Li JJ. Circadian variation in myocardial ischemia: the possible mechanisms involving in this phenomenon. Med Hypotheses 2003; 61(2): 240-243.

13. Smolensky MH, Labreque G. Chronotherapeutics. Pharm. News 1997; 2: 10-16.

14. Washington N, Wilson CG. Can oral controlled drug delivery meet the challenges posed by chronotherapeutics? [Cited 2009 May 28]. Available from: http://www.egalet.com/multimedia/Chronothera py May 061.pdf

15. Lemmer B. Circadian rhythms and drug delivery. $J \mathrm{~J}$ Contr Release. Controlled Release 1991; 16:63-74

16. Lemmer B, Bruguolle B. Chronokinetics: are they clinically relevant? Clin Pharmacokinet 1994; 26: 419-427.

17. Lemmer B. and Nold G. Circadian changes in estimated hepatic blood flow in healthy subjects. $\mathrm{Br} J$ Clin PharmacolBr. J. Clin. Pharma. 1991; 32: 627-629.

18. Shiga, Fujimura A, Tateishi T, Ohashi K. and Ebihara $A$. Differences of chronopharmacokinetic profiles between propranolol and atenolol in hypertensive patients. J Clin Pharmacol 1993; 33: 756-761.

19. Lemmer B, Portaluppi R. Chronopharmacology of cardiovascular diseases. In: Redfern $\mathrm{PH}$ Lemmer B. editors. Physiology and Pharmacology of Biological Rhythms. Mannheim: Springer-Verlag; 1997. p.251-283.

20. Ollagnier $M$, Decousus $H$, Cherrah $Y$, Levi $F$, Mechkouri M, Queneau $P$, Reinberg $A$. Circadian changes in the pharmacokinetics of oral ketoprofen. Clin Pharmacokin 1987; 12: 367-378.

21. Clench J, Reinberg A, Dziewanowska Z, Ghata, Smolensky $M$. Circadian changes in the bioavailability and effects of indomethacin in healthy subjects. Eur J Clin Pharmacol 1981; 20: 359-369.

22. Guissou P, Cuisinaud G, Llorca G, Lejeune E, Sassard J. Chronopharmacokinetic study of a prolonged release form of indomethacin. Eur $J$ Clin Pharmacol 1983; 24: 667-670. 
23. Reinberg A, Levi F, Touitou Y. Clinical pharmacokinetic changes in a sustained release preparation of ketoprofen. Annu Rev Chronopharmacol 1986; 3: 317-320.

24. Conte $U$, Colombo $P$, La Manna A, Gazzaniga A, Sangalli ME, Giunchedi P. A new ibuprofen pulsed release oral dosage form. Drug Dev Ind Pharm 1989; 15: 2583-2596.

25. Conte $U$, Giunchedi $P$, Maggi L, Sangalli ME, Gazzaniga A, Colombo $\boldsymbol{P}$, La Manna $A$. Ibuprofen delayed release dosage forms: a proposal for the preparation of an in vitro/in vivo pulsatile system. Eur J Pharm Biopharm. 1992; 38: 209-212.

26. Conte $U$, Maggi $L$, Torre $M L P$, Giunchedi $P$ and $L a$ Manna A. Press- coated tablets for timeprogrammed release of drugs. Biomaterials 1993; 14: 1017-1023.

27. Vyas SP, Sood A, Venugoplan P. Circadian rhythm and drug delivery design. Pharmazie 1997; 52 : 815-820.

28. Bogin RM, Ballard RD. Treatment of nocturnal asthma with pulsed-release albuterol. Chest 1992; 102: 362-366.

29. Conte $U$, Maggi L. Modulation of the dissolution profiles from Geomatrix@ multi-layer matrix tablets containing drug of different solubility. Biomaterials 1996; 17: 889-896.

30. Ghika J, Gachoud JP, Gasser U. Clinical efficacy and tolerability of a new levodopa/benserazide dual-release formulation in parkinsonian patients. Clin Neuropharmacol 1997; 20: 130139.

31. Ueda S, Hata T, Asakura S, Yamaguchi H, Kotani $M$, Ueda $Y$. Development of a novel drug release system, time controlled explosion system (TES). Part 1. Concept and design. J Drug Target 1994; 2(1): 35-44.

32. Ueda S, Yamaguchi H, Kotani M. Development of a novel drug release system, time controlled explosion system (TES). II. Design of multiparticulate TES and in vitro drug release properties. Chem Pharm Bull 1994; 42: 359363.

33. Narisawa $S$, Nagata $M$, Danyoshi $C$, Yoshino $H$, Murata K, Hirakawa $Y$, Noda $K$. An organic acid-induced sigmoidal release system for oral controlled release preparations. Pharm Res 1994; 11: 111-116.

34. Narisawa $S$, Nagata $M$, Ito $T$, Yoshino $H$, Hirakawa $Y$, Noda K. Drug release behavior in gastrointestinal tract of beagle dogs from multiple unit type rate-controlled or timecontrolled release preparations coated with insoluble polymer-based film. J Contr Release J. Controlled Release 1995; 33: 253-260.
35. Narisawa $S$, Nagata $M$, Hirakawa $Y$, Kobayashi $M$, Yoshini $H$. An organic acid-induced sigmoidal release system for oral controlled release preparations.2. Permeability enhancement of Eudragit RS coating led by the physicochemical interactions with organic acid. J Pharm Sci. 19965; 85: 184-188.

36. Gazzaniga $A$, Sangalli $M$, Giordano $F$. Oral Chronotopic® drug delivery systems: Achievement of time and/or site specifity. Eur $J$ Biopharm 1994; 40: 246-250.

37. Matsuo $M$, Nakamura $C$, Arimori $K$, Nakano $M$. Evaluation of hydroxyethylcellulose as a hydrophilic swellable material for delayedrelease tablets. Chem Pharm Bull 1995; 43: 311-314.

38. Marvola $M$, Sirkiä $T$. Controlled release pharmaceutical preparations. Finnish Patent 93924, 26.6.1995.

39. Sirkiä T, Marvola M, Nikunen S, Tuuri L, Happonen I. Biopharmaceutical chracterization of new double-unit controlled-release furosemide tablets. Acta Pharm Fenn 1992; 101: 205-214.

40. Sirkiä T, Mäkimartti, Liukko-Sipi S, Marvola M. Development and biopharmaceutical evaluations of a new press-coated prolongedrelease salbutamol sulphate tablet in man. Eur J Pharm Sci 1994; 1: 195-201.

41. Sirkiä T, Niemi J, Marvola M, Lindqvist T, Happonen l. Effect of potassium carbonate and viscosity grade of hydroxypropylmethylcellulose on bioavailability of furosemide from presscoated prolonged-release tablets. STP Pharma Sci 1994; 4: 257-263.

42. Sirkiä $T$, Salonen $H$, Veski $P$, Jürjenson $H$, Marvola M. Biopharmaceutical evaluation of new prolonged-release press-coated ibuprofen tablets containing sodium alginate to adjust drug release. Int J Pharm 1994; 107: 179-187.

43. Magruder PR, Barclay B, Wong PSL. Composition comprising salbutamol. U.S. patent 4,751,071.1988.

44. Cutler N, Anders R, Stanford S, Sramed J, Awan N, Bultas J, Lahari A, Woroszylska M. Placebocontrolled evaluation of three doses of a controlled-onset, extended-release formulation of verapamil in the treatment of stable angina pectoris. Am J Cardiol 1995; 75: 1102-1106.

45. Anwar YA, White WB. Chronotherapeutics for cardiovascular disease. Drugs 1998; 55: 631643.

46. Hedben J, Wilson $C$, Spiller $R$, Gilchrist $P$, Blackshaw E, Frier M. Perkins A. Regional differences in quinine absorption from the undisturbed human colon assessed using a timed release delivery system. Pharm Res 1999; 16: 1087-1092. 